\title{
Vascular Endothelial Growth Factor, Irradiation, and Axitinib Have Diverse Effects on Motility and Proliferation of Glioblastoma Multiforme Cells
}

\author{
Reinhardt Krcek ${ }^{1}$, Veronika Matschke ${ }^{1}$, Verena Theis ${ }^{1}$, Irenäus Anton Adamietz ${ }^{2}$, \\ Helmut Bühler ${ }^{3}$ and Carsten Theiss ${ }^{1 *}$
}

'Department of Cytology, Institute of Anatomy, Ruhr-University Bochum, Bochum, Germany, ${ }^{2}$ Department of Radiotherapy and Radio-Oncology, University Medical Centre Marien Hospital, Ruhr-University Bochum, Herne, Germany, ${ }^{3}$ Institute for Molecular Oncology, Radio-Biology and Experimental Radiotherapy, University Medical Centre Marien Hospital,

Ruhr-University Bochum, Herne, Germany

OPEN ACCESS

Edited by:

Giuseppe Giaccone, Georgetown University,

United States

Reviewed by: Yongmei Song,

Peking Union Medical College Hospital (CAMS), China

Monica Venere,

The Ohio State University

Columbus, United States

*Correspondence: Carsten Theiss carsten.theiss@rub.de

Specialty section: This article was submitted to Cancer Molecular Targets and Therapeutics, a section of the journal Frontiers in Oncology

Received: 24 May 2017 Accepted: 08 August 2017 Published: 22 August 2017

Citation:

Krcek R, Matschke V, Theis V, Adamietz IA, Bühler $H$ and Theiss $C$ (2017) Vascular Endothelial Growth Factor, Irradiation, and Axitinib Have

Diverse Effects on Motility and Proliferation of Glioblastoma Multiforme Cells.

Front. Oncol. 7:182. doi: 10.3389/fonc.2017.00182
Glioblastoma multiforme (GBM) is the most common primary brain tumor. It is highly aggressive with an unfavorable prognosis for the patients despite therapies including surgery, irradiation, and chemotherapy. One important characteristic of highly vascularized GBM is the strong expression of vascular endothelial growth factor (VEGF). VEGF has become a new target in the treatment of GBM, and targeted therapies such as the VEGF-receptor blocker axitinib are in clinical trials. Most studies focus on VEGF-induced angiogenesis, but only very few investigations analyze autocrine or paracrine effects of VEGF on the tumor cells. In this study, we examined the impact of VEGF, irradiation, and axitinib on cell proliferation and cell motility in human GBM cell lines U-251 and U-373. VEGF receptor 2 was shown to be expressed within both cell lines by using PCR and immunochemistry. Moreover, we performed 24-h videography to analyze motility, and a viability assay for cell proliferation. We observed increasing effects of VEGF and irradiation on cell motility in both cell lines, as well as strong inhibiting effects on cellular motility by VEGF-receptor blockade using axitinib. Moreover, axitinib diminished irradiation induced accelerating effects. While VEGF stimulation or irradiation did not affect cell proliferation, axitinib significantly decreased cell proliferation in both cell lines. Therefore, the impairment of VEGF signaling might have a crucial role in the treatment of GBM.

Keywords: glioma, cell motility, cell proliferation, vascular endothelial growth factor, irradiation, axitinib, videography

\section{INTRODUCTION}

Glioblastoma multiforme (GBM) is the most common primary brain tumor in adults and is highly malignant. Its etiology is widely unknown with an incidence of 3-4/100,000 and a poor outcome for the patients. The tumor is preferentially located in the frontal lobes of the supratentorial compartments, but can also occur focally, multifocally or diffusely in all cortical areas $(1,2)$. The current standard therapy is a combination of surgery, a fractionated radiotherapy and a chemotherapeutic

Abbreviations: GBM, glioblastoma multiforme; VEGF, vascular endothelial growth factor; VEGF-R1, VEGF receptor 1; VEGF-R2, VEGF receptor 2. 
treatment with DNA alkylating temozolomide. However, it offers only a median survival time of 15 months (2). One reason for this poor prognosis is the high invasiveness of GBM into the brain parenchyma, hindering a complete resection in most cases (3-5). Despite of an improvement using radiotherapy to reduce the tumor mass, it is not possible to achieve high survival rates (6).

As GBM shows high levels of vascularization (1), one new target is the vascular endothelial growth factor (VEGF) which plays an important role, especially in angiogenesis $(4,7)$. VEGF was first described in 1983 as a protein in the tumor ascites fluids of guinea pigs, where it promoted vascular permeability (8). It is a dimeric polypeptide and constitutes a gene family including VEGF-A, VEGF-B, VEGF-C, VEGF-D, and placental growth factor. VEGF-A, in the following referred to as VEGF, is the most important and best known form of VEGF, and is one of the key regulators in angiogenesis, stimulating proliferation, chemotaxis, survival, and permeability of endothelial cells (7,9-11). VEGF is the activating ligand of two receptor-tyrosine kinases, VEGF receptor 1 (VEGF-R1) and VEGF receptor 2 (VEGF-R2). While VEGF-R1 is supposed to play a role mainly as a modulator of VEGF-R2mediated signaling (12), the main effects in angiogenesis occur via activation of VEGF-R2, for instance through activation of Cdc42 and SAPK2/p38, which leads to a remodeling of actin (13).

In the brain, VEGF is mainly expressed by neurons, astrocytes, and endothelial cells (14). Some stimuli for the release of VEGF are known as hypoxia inducible factors, which are activated by insufficient blood supply, for instance in fast growing cancer (15). Another mechanism of VEGF secretion is mediated by stimulation of MAPK dependent pathways, for example because of irradiation (16).

It is well described that several tumors like hepatocellular cancer or the highly vascularized GBM produce high levels of VEGF to force neoangiogenesis and growth (17-19). Therefore, VEGF became a target in the treatment of cancer. One example is bevacizumab, the first humanized antibody against VEGF, which has been proved to be a successful supplementation to standard therapies in colorectal cancer $(20,21)$. More recently, several clinical trials are testing the efficiency of bevacizumab in high-grade glioma, offering encouraging results in terms of an increase in the progression free survival period $(22,23)$. Another candidate for anti-angiogenic therapy is the tyrosine kinase inhibitor axitinib, a selective inhibitor of the VEGF receptors 1, 2, and 3, passing through phase III of clinical testing in renal carcinoma $(24,25)$ and in phase II for GBM (NCT01562197). Besides stimulating angiogenesis, VEGF also shows proliferative effects on several tumors (26). Furthermore, it has been shown that VEGF enhances proliferation and motility in glial cells (27). Based on these data derived from cultured astrocytes, we analyzed the impact of VEGF, irradiation and axitinib on proliferation and motility in the two different human GBM cell lines U-251 and U-373.

\section{MATERIALS AND METHODS}

\section{Materials}

VEGF-A (Sigma-Aldrich, V4512, USA) and axitinib(Selleckchem, S1005, USA) was added to cell culture medium in a concentration of 0.1 and $10 \mu \mathrm{g} / \mathrm{ml}$, respectively. To investigate the impact of therapeutic irradiation, cells were irradiated with the linear accelerator, Elekta Synergy S, at $5 \mathrm{~Gy} / \mathrm{min}$ at the university clinic Marien Hospital Herne (Germany). Cell medium was changed $1 \mathrm{~h}$ after irradiation.

\section{Cell Lines}

Two human glioblastoma cell lines were used. U-251 MG human brain glioblastoma cell line was obtained from CLS (Heidelberg, Germany) and U-373 MG was a generous gift from Dr. Bardenheuer (Essen, Germany). The cell lines U-251 and U-373 were routinely grown in Dulbecco's modified eagle medium (DMEM) with $4.5 \mathrm{~g} / \mathrm{l} \mathrm{D}$-Glucose, $3.7 \mathrm{~g} / 1 \mathrm{NaHCO}_{3}$, stable glutamine and Na-pyruvat (Biochrom AG, FG 0445, Germany). Media were supplemented with $10 \%$ sterile fetal bovine serum (Biochrom AG, S 0115) and 1\% penicillin-streptomycin (Sigma-Aldrich, P0781). Cell lines were maintained at $37^{\circ} \mathrm{C}, 5 \% \mathrm{CO}_{2}$, and $90 \%$ humidity.

\section{Immunohistochemistry}

Experiments started 1 day after seeding of the GBM cell lines at a density of 5,000 cells/ $12 \mathrm{~mm}$ cover slip. The cells were fixed with $4 \%$ paraformaldehyde for $10 \mathrm{~min}$, followed by permeabilization with $0.1 \%$ Tween (VWR, 663684B, USA) in PBS for $60 \mathrm{~min}$. Additionally, unspecific binding sites were blocked with goatserum (Sigma-Aldrich, G9023, 10\% in PBS) and bovine serum (Sigma-Aldrich, B9433, 3\% in PBS) adding 0.3 M glycine (Biomol, 04943, Germany). After washing with PBS, cells were incubated with rabbit anti-VEGF-R2 antibody overnight (Abcam, ab39638, United Kingdom, 1:300 in PBS), followed by incubation with AlexaFluor 488 anti-rabbit IgG (Molecular Probes, A-11008, USA, 1:250 in PBS) for $75 \mathrm{~min}$ and then subsequently treated with rhodamine-phalloidin for 30 min (Sigma-Aldrich, P1951, 1:20 in PBS). Further bisBenzimide H 33342 trihydrochloride (Hoechst, Sigma-Aldrich, B2261, 1:1,000 in PBS, $20 \mathrm{~min}$ ) was applied to counterstain the cell nuclei. Finally, the cover slips were mounted on microscope slides with fluoromount mounting medium (Dako, S3023, Germany).

\section{Reverse Transcription-PCR}

To prove the existence of VEGF-R1 (FLT1) und VEGF-R2 $(K D R)$ mRNA in GBM cell lines a qualitative PCR was performed. Total RNA was isolated using ReliaPrep RNA Cell Miniprep System (Promega, Z6011, USA) according to manufacturer's protocol. cDNA was synthesized from $1 \mu \mathrm{g}$ of total RNA using Promega Reverse Transcription System (Promega, Z6011, USA). We used prior published specific primer sequences for amplification of the gene of interest: FLT1-forward: ATCATTCCGAAGCAAGGTGTG, reverse: AAACCCATTTGGCACATCTGT, KDR-forward: AGGCAGCTCACAGTCCTAGAGC, reverse: GTCTTTTCC TGGGCACCTTCTA (28). PCR was performed using the GoTaq G2 Hot Start Green Master mix (Promega, M7422). PCR products were analyzed by agarose gel electrophoresis before verification by sequencing.

\section{Videography}

Time-laps videography was performed as described previously (29). In brief, after seeding 50,000 cells $/ 3.5-\mathrm{cm}$ well, cells were treated with 
$\operatorname{VEGF}(0.1 \mu \mathrm{g} / \mathrm{ml})$, axitinib $(10 \mu \mathrm{g} / \mathrm{ml})$, and/or radiation (2 Gy) on the next day. Medium was changed $1 \mathrm{~h}$ after irradiation containing the reagents. At the same time, the medium of non-irradiated glioma cells was changed. Videography started $2 \mathrm{~h}$ after adding fresh medium.

Cells were maintained in a $5 \% \mathrm{CO}_{2}$ atmosphere at $37^{\circ} \mathrm{C}$ and observed for $24 \mathrm{~h}$, taking images every $15 \mathrm{~min}$ using an inverse microscope (Zeiss Axiovert 25) equipped with a $10 \times$ objective (Zeiss A-plan 10, NA 0.25) and an Olympus E420 camera. For analysis of cellular motility, cells were tracked throughout the image stack and then analyzed by the Chemotaxis and Migration tool V2.0 $\left(\right.$ ibidi $\left.^{\circledR}\right)$. All cells that stayed in focus for at least $5 \mathrm{~h}$ were examined. The measured velocity of each cell was normalized to the average of the control conditions and plotted into a bar chart.

\section{Proliferation Assay}

5,000 cells per well were seeded in a 96-well plate (Sarstaedt, Germany). On the next day, cells were treated with irradiation, VEGF, and/or axitinib. Fresh medium was added $1 \mathrm{~h}$ after irradiation including the reagents, with the same procedure for non-irradiated cells. $24 \mathrm{~h}$ after treatment, cells were incubated with MTS reagents (Promega CellTiter 96 ${ }^{\circledR}$ AQueous NonRadioactive Cell Proliferation Assay, G5421) for 2 h. Thereafter, absorbance at $450 \mathrm{~nm}$ was measured with a Multiscan Ascent 354 (Labsystems, Heidelberg, Germany). The measured values were normalized to the average of the control conditions and plotted into a bar chart.

\section{VEGF ELISA-Analysis of Supernatant}

One million cells were seeded in a $6-\mathrm{cm}$ petri-dishe (Sarstedt, Germany). After $24 \mathrm{~h}$ the medium was replaced by $4 \mathrm{ml} \mathrm{DMEM}$ containing $1 \%$ fetal bovine serum. Subsequently both cell lines were irradiated with $2 \mathrm{~Gy}$. On the next day, the supernatant was removed, diluted 1:5 in DMEM containing 1\% fetal bovine serum, and the VEGF ELISA was performed as described in the manufacturer's protocol (Human VEGF Quantikine ELISA Kit, Bio-Techne, DVE00, Wiesbaden, Germany).

\section{Statistical Analysis}

Statistical analyses of the data were performed with Prism 5.0 (Graph Pad Inc., La Jolla, CA, USA). Data represent mean values of at least three independent experiments \pm SE of the mean (SEM). Experiments were analyzed by one-way ANOVA with Bonferroni multiple comparison post-test. $p$-Values $p \leq 0.05$ were considered statistically significant.

\section{RESULTS}

\section{VEGF Receptor Expression}

In line with former studies the expression of VEGF-R2 (KDR) mRNA was verified by PCR and immunohistochemistry $(30,31)$. Figure 1 shows that the human glioblastoma cell lines U-251 and U-373 both express VEGF-R1 (FLT1) and VEGF-R2 (KDR) $(\mathrm{A}, \mathrm{B})$. DNA sequencing of the PCR products confirmed these results $(\mathrm{C}, \mathrm{D})$. Moreover, VEGF-R2 $(K D R)$ is much stronger expressed than VEGF-R1 (FLT1) in both cell lines (E). In addition, the distribution of VEGF-R2 was detected immunohistochemically within the cytoplasm as well as along the cell membrane in both GBM cell lines (F).

\section{Quantitative Analysis of Cellular Motility}

To determine the effects of VEGF, irradiation, or axitinib treatment on cell motility, $24 \mathrm{~h}$ videography was performed (Figure 2). A set of samples of time-lapse videography of U-373 cells is shown in Figure $\mathbf{2 A}$ as well as a representative plot of tracked cells Figure 2B. All values being compared to untreated controls were presented for both cell lines: U-251 (Figure 2C) and U-373 (Figure 2D). Adding VEGF significantly enhanced the velocity of cellular motility in U-251 (from $1.0 \pm 0.051$ untreated to $1.18 \pm 0.039, n=60, p<0.001)$, and in U-373 (from $1.0 \pm 0.039$ untreated to $1.17 \pm 0.041, n=60, p<0.01$ ). Irradiation also showed significantly increasing effects in U-251 $(1.25 \pm 0.04, n=60, p<0.001)$ and in U-373 cells $(1.27 \pm 0.057$, $n=60, p<0.001)$. However, in U-251 cells the combination of adding VEGF plus irradiation does not lead to higher levels of cellular motility, compared with cells only treated with VEGF or $2 \mathrm{~Gy}(1.19 \pm 0.042)$. In U-373 the combined treatment with VEGF and 2 Gy had a significant effect on cell velocity, compared with VEGF alone $(1.31 \pm 0.045, n=60, p$ (VEGF) $<0.05)$. Axitinib treatment had pronounced and significant decelerating effects on both cell lines, U-251 $(0.61 \pm 0.031, n=60$, $p<0.0001)$, and U-373 (0.56 $\pm 0.034, n=60, p<0.0001)$. The combinations of VEGF and axitinib (U-251: $0.71 \pm 0.066$, $n=60, p<0.001$; U-373: $0.70 \pm 0.049, n=60, p<0.0001)$ or irradiation with 2 Gy plus axitinib treatment showed similar effects as with axitinib alone in U-251 $(0.69 \pm 0.028, n=60$, $p<0.0001)$, and in U-373 (0.65 $\pm 0.044, n=60, p<0.001)$. The partly pronounced effects of irradiation plus axitinib were not significant with respect to axitinib alone. The combination of all three treatments, irradiation (2 Gy), VEGF, and axtinib exhibited a significant decrease in cellular motility compared to control in both cell lines (U-251: $0.79 \pm 0.06, n=60, p<0.001$; $\mathrm{U}-373: 0.76 \pm 0.062, n=60, p<0.001)$.

\section{Analysis of VEGF Levels in the Supernatant in U-251 and U-373}

Additionally, we analyzed the amount of VEGF within the supernatant of U-251 and U-373 $24 \mathrm{~h}$ after 2 Gy irradiation (Figures 2E,F). In at least six independent experiments for each cell line the supernatant of U-373 (Figure 2F) revealed a significant increase of VEGF $(3.461 \pm 0.068$ vs. untreated $3.083 \pm 0.032$ pg per 1,000 cells, $n=6, p<0.05$ ), whereas in U-251 (Figure 2E) the amount of VEGF in the supernatant did not show any significant changes after irradiation.

\section{Impact of VEGF and Irradiation on Cell Proliferation}

To investigate the influence of treatment on GBM proliferation, the Promega MTS assay was used, with at least three independent experiments for each cell line (Figures 3A,B). VEGF, irradiation with $2 \mathrm{~Gy}$, or a combination of irradiation and VEGF had no significant effects on proliferation in all 

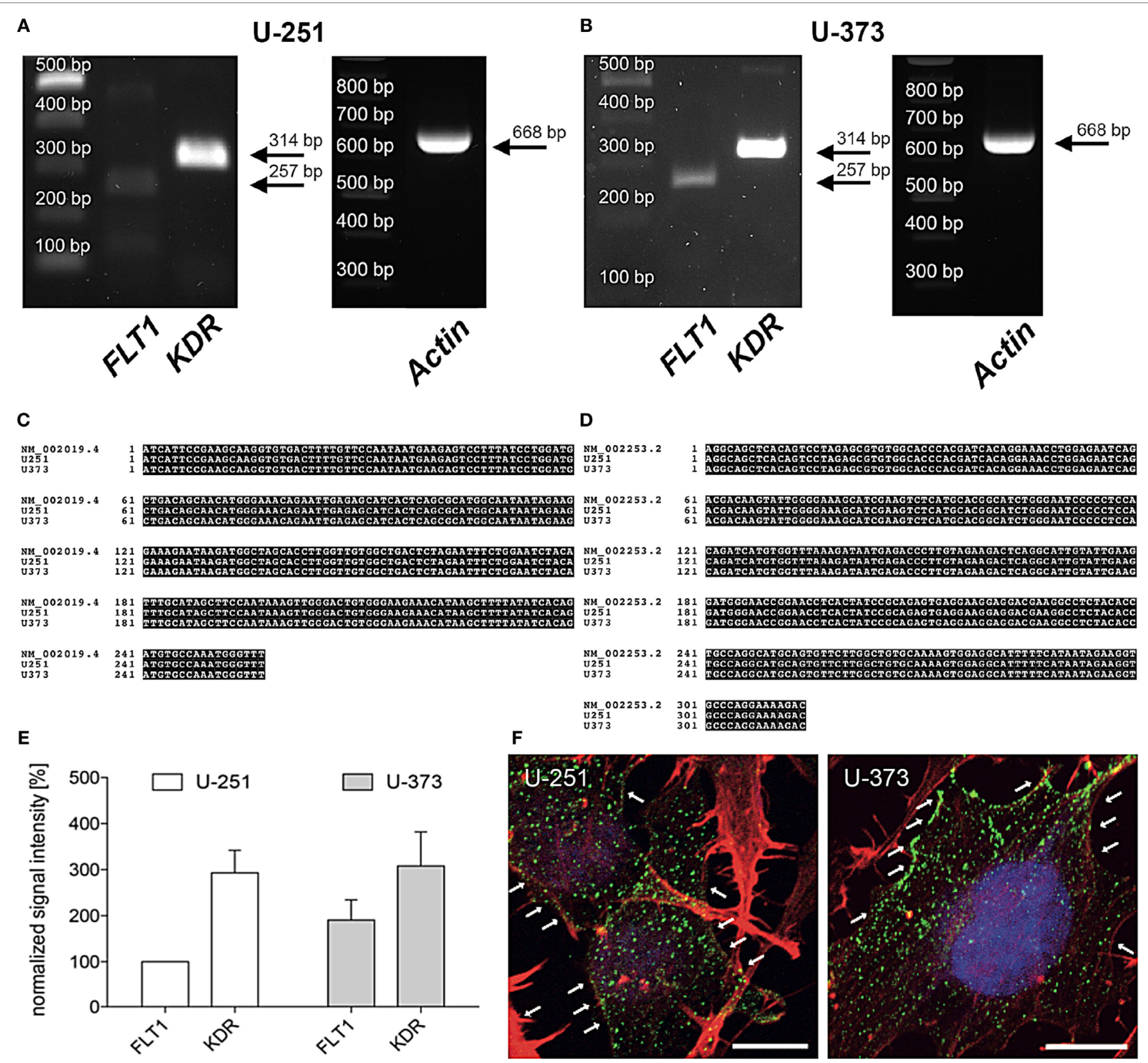

FIGURE 1 | Expression of vascular endothelial growth factor (VEGF)-R2 (KDR) in U-251 and U-373 glioblastoma cell lines. (A,B) VEGF-R1 (FLT1) as well as VEGF-R2 (KDR) are expressed in both cell lines U-251 (A) and U-373 (B). $\beta$-Actin was used as housekeeping gene. PCR products were isolated and confirmed by DNA sequencing. (C,D) Sequence of amplified PCR product for FLT1 (C) and KDR (D) matches their specific database entries (FLT1 - NM_002019.4; KDR NM_002253.2) and were proven to be unique in human glioblastoma cell lines U-251 as well as in U-373 by comparison with a database (Blast 2.2, U.S. National Centre for Biotechnology Information, Bethesda, MD, USA) (E). Semi-quantitative analysis of gene expression normalized to $\beta$-Actin and compared to the expression of U-251-FLT (100\%). Data are shown as mean \pm SEM. $n=3$. (F) Both glioblastoma multiforme cell lines express VEGF-R2 (green dots, arrows) in the cytoplasm as well as along the cell membrane. Counterstaining of the actin cytoskeleton is given in red as well as cell nuclei staining with DAPI in blue. Scale bars: $10 \mu \mathrm{m}$.

tested cell lines. However, the VEGF receptor blocker axitinib decreased the proliferation of U-251 $(0.752 \pm 0.032, n=19$, $p<0.001)$, and of $\mathrm{U}-373(0.798 \pm 0.017, n=20, p<0.001)$. Similar results were obtained for the combination of axitinib and irradiation in U-251 $(0.844 \pm 0.029, n=25, p<0.001)$, and in U-373 $(0.8 \pm 0.032, n=20, p<0.001)$. In U-251, there was a significant increase in proliferation comparing axitinib to irradiation plus axitinib $(0.752 \pm 0.032$ vs. $0.844 \pm 0.029$, $p<0.05)$, whereas $\mathrm{U}-373$ showed no significant difference between these two treatments.

\section{DISCUSSION}

High-grade glioma patients have a poor prognosis despite all the options of today's medicine. It has been shown that high VEGF expression correlates with a bad prognosis in glioma patients (32). 
It has also been demonstrated that there is a relationship between the secretion of VEGF and irradiation since this therapeutic intervention leads to enhanced secretion of VEGF in combination with activation of VEGF signaling pathways (16). Furthermore, high VEGF levels seem to act as a survival factor for irradiated cancer cells, including glioma $(30,33,34)$. This dilemma of therapeutic irradiation is accompanied by increased angiogenesis which is associated with higher VEGF levels after irradiation. Therefore, clinical and experimental trials suggest the combination of radiation and antiangiogenic therapy to overcome this problem (35-37); however, highly innovative and effective approaches are still missing.

In this study, we could underline stimulating effects of VEGF and also of irradiation on the motility of human GBM cell lines, whereas there were no similar effects on cell proliferation. On the other hand, the blockage of VEGF receptors by axitinib diminished VEGF and irradiation mediated effects. Moreover, these axitinib treated cells showed decreased proliferation and motility compared to controls. Additional VEGF did not enhance the effects of irradiation. We conclude that its impact is mainly dependent on autocrine and paracrine stimulation of the VEGF receptor by a rapid secretion of VEGF after irradiation, as has been proven in glioma (16).

\section{VEGF and Radiation Influence Cell Motility of GBM Cell Lines}

Cellular motility plays an important role in the metastasis of GBM, which is characterized by fast relapses in the brain after

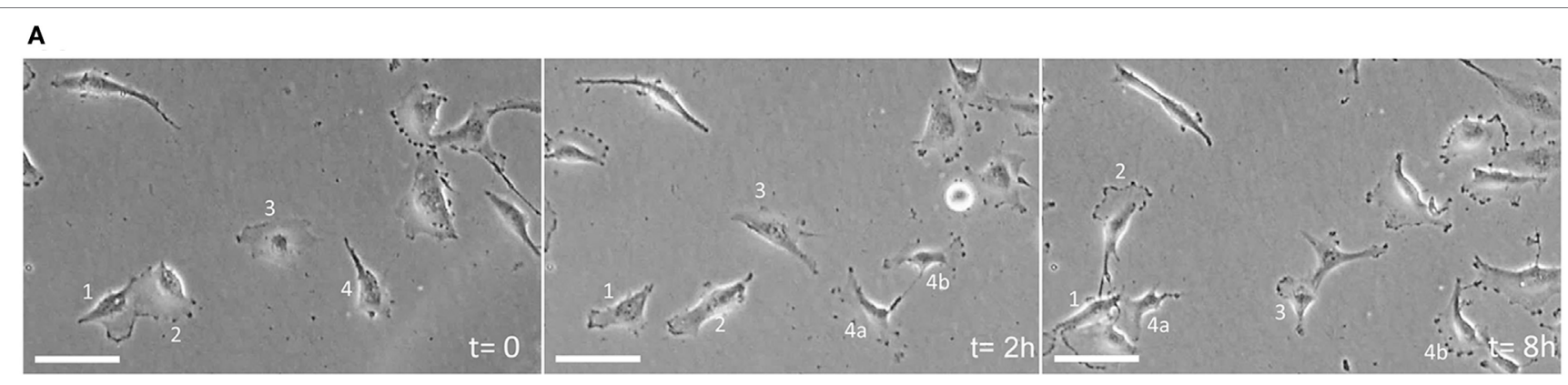

B
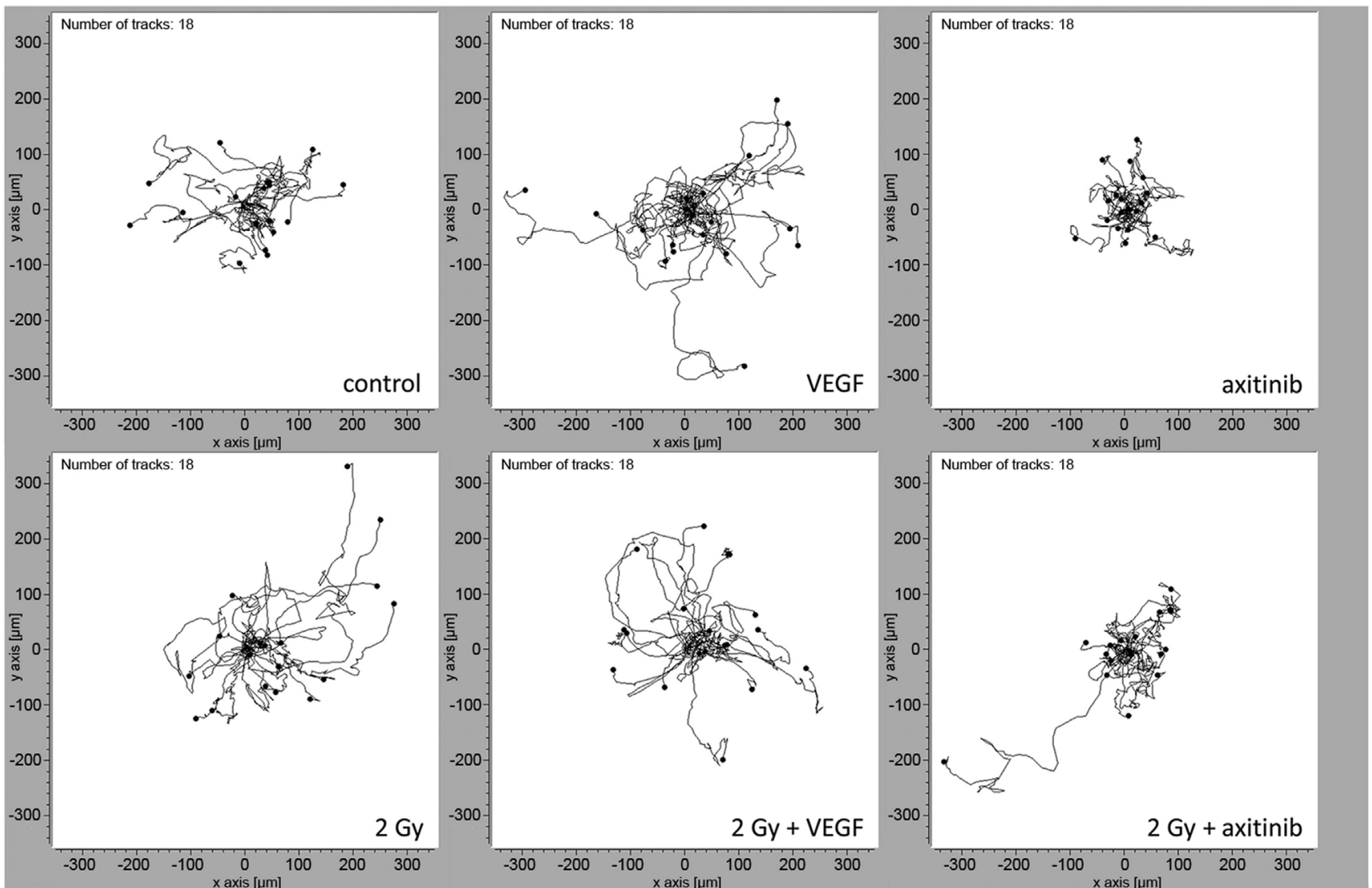

FIGURE 2 | Continued 
C

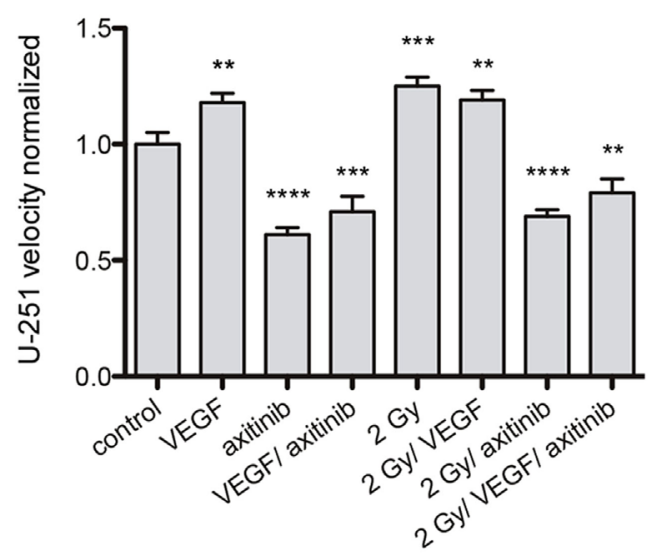

E

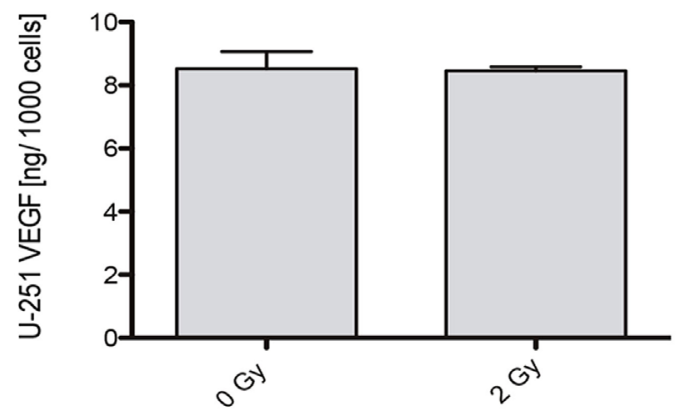

D

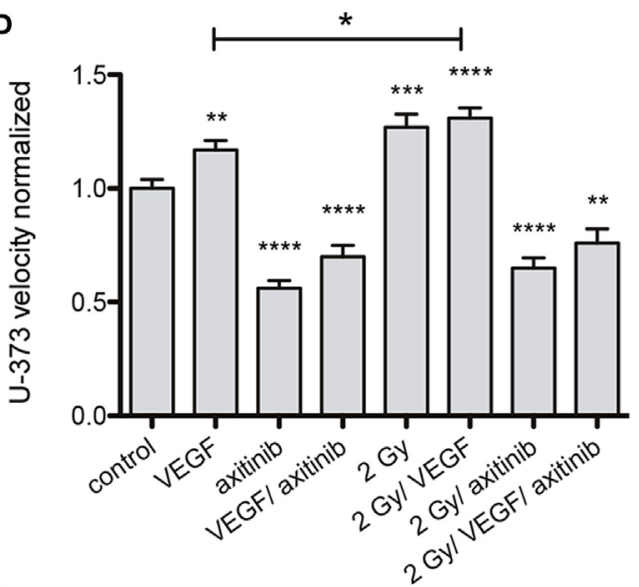

$\mathbf{F}$

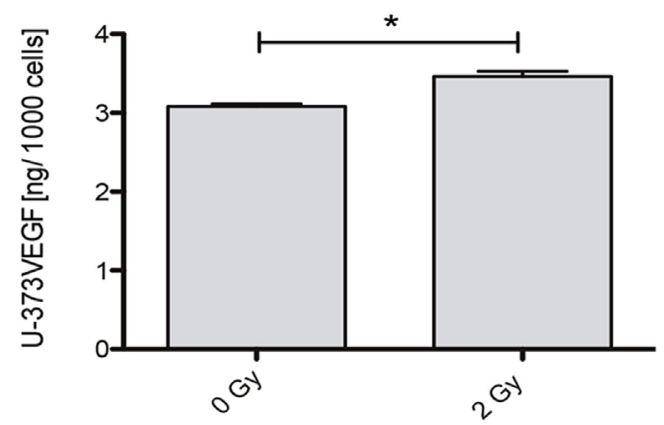

FIGURE 2 | Influence of vascular endothelial growth factor (VEGF), axitinib, or irradiation with 2 Gy photons on the motility of glioblastoma multiforme cell lines U-251 and U-373. The motility of the cells was analyzed by time-laps videography. Cells were tracked and analyzed with the ibidi chemotaxis and migration tool. (A) Examples from an image stack of Videography. Some cells migrate fast (2), some slowly (3), some even do not migrate (1). Dividing cells (4) often keep contact over longer periods of time (4a, $4 \mathrm{~b})$. Scale bars: $50 \mu \mathrm{m}$. (B) Migration of U-373 glioblastoma cells under varied conditions. Depicted are the tracked cells in representative fields of view. The software merges all starting points in the origin to get an explicit view of the paths migrated by the cells. It is clearly visible that the migration is undirected (an advantage of videography over other methods to analyze migration). It is notable that some irradiated cells are able to escape the inhibition by axitinib. (C,D) The motility of U-251 and U-373 cells is increased by VEGF as well as by irradiation. In U-373, a combination of both leads to a significant increase in velocity compared to VEGF alone (D), in U-251 no additive effects could be observed. In contrast, axitinib diminishes the motility of untreated cells and the elevated motility after irradiation as well. VEGF and axitinib were added in concentrations of 0.1 and $10 \mu \mathrm{g} / \mathrm{ml}$, respectively. (E,F) $24 \mathrm{~h}$ after 2 Gy irradiation the amount of VEGF in the supernatant of U-251 and U-373 was analyzed. In U-251 there were no significant changes detectable, whereas in U-373 cells VEGF was significantly increased (F). Data are shown as mean \pm SEM. Data were tested for significance using one-way ANOVA with Bonferroni multiple comparison post-test. Significant differences are indicated by ${ }^{\star} p<0.05 ;{ }^{* \star} p<0.01 ;{ }^{* \star *} p<0.001 ;{ }^{* \star \star} p<0.0001$.
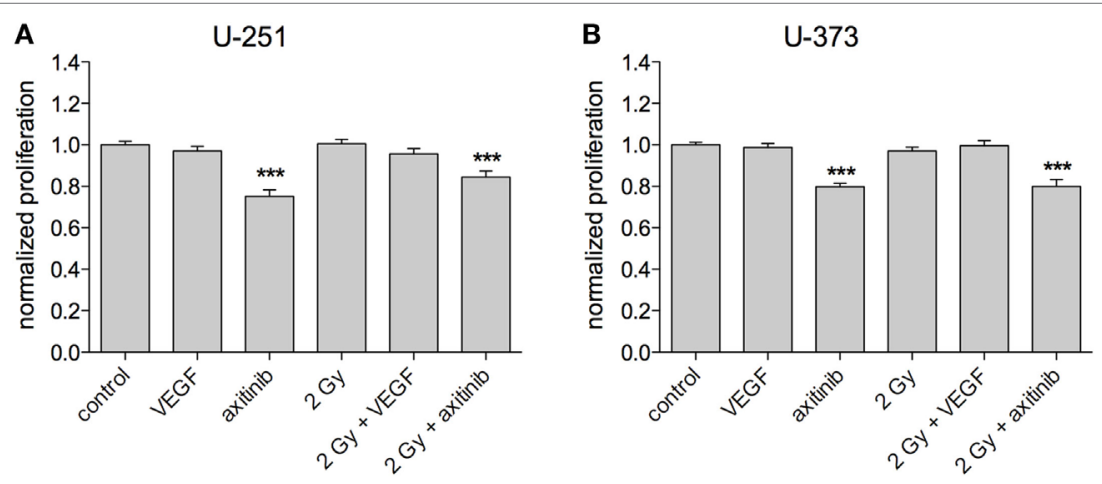

FIGURE 3 | Influence of vascular endothelial growth factor (VEGF), axitinib, or irradiation with 2 Gy photons on the proliferation of glioblastoma multiforme cell lines U-251 and U-373. (A,B) Axitinib impairs the proliferation of irradiated and non-irradiated U-251 and U-373 cells. VEGF, irradiation, or the combination of both has no significant effect on cell proliferation. The proliferation of the cells was analyzed by a modified MTS-test. VEGF and axitinib were added in concentrations of 0.1 and $10 \mu \mathrm{g} / \mathrm{ml}$, respectively. Data are shown as mean \pm SEM. Data were tested for significance using one-way ANOVA with Bonferroni multiple comparison post-test. Significant differences are indicated by ${ }^{* \star} p<0.001$. 
surgery and other therapies. Our study points out the importance of VEGF in cellular motility. We observed stimulating effects by adding high concentrations of VEGF and comparable stimulating effects of irradiation in both GBM cell lines. Besides this we could reduce cellular motility in these cell lines using the VEGF receptor inhibitor axitinib, which points to VEGF being a key player in an autocrine stimulation of motility. Nevertheless, cellular motility was not completely impaired by axitinib, probably due to other signaling pathways that provoke migration, for instance through activation of the epidermal growth factor receptor (EGFR) pathways $(38,39)$. Our results match with those of Kil et al. (36), who showed an increased transwell migration of U-251 cells after VEGF stimulation or incubation in medium collected from GBM cells $72 \mathrm{~h}$ after irradiation. In that study, the stimulating effects of the irradiated medium could be blocked by VEGF antibodies, which were directly supplemented. These results in chemotactic experiments display the role of VEGF as a cytokine rather than its influence on the general motility of the cells. But a strong hint is given, that irradiation can stimulate the secretion of VEGF.

In the present study, we extend this previous knowledge to U-373 cells indicating a general mechanism at least in glioblastoma cells. We could show that VEGF is not only a chemoattractant, but also exerts stimulating effects on the general motility of these cells, too. Using videography as a technique to track living cells, we showed that there was an increased amount of undirected migration after VEGF exposure. However, our observations contradict the results of Ghosh et al. (40) who revealed a decrease in the migration of GBM cells after 2 Gy irradiation, but a strong increase at lower doses. This difference between the studies could be due to different radiation sources, since Ghosh et al. used a cobalt gamma radiation unit. Different dose rates and different photon energies might result in different responses from the cells to the same overall dose. However, we know from the data published by Hovinga et al. (41) and Kil et al. (36) that VEGF is a chemoattractant for GBM cells. Additionally, these groups also demonstrated that irradiation promotes secretion of VEGF in U-251 cells. In the present study, we detected a slight increase in VEGF levels in the supernatant of U-373 after irradiation, but not in U-251. It is likely that the amount of VEGF secretion in U-251 positively correlates with the dose of irradiation and the time point of VEGF measurement. Here, we used a single dose of 2 Gy irradiation, which reflects the dose that is common in fractionated radiotherapies of GBM (42), whereas other studies showing an increase in VEGF used different doses up to $20 \mathrm{~Gy}(36,41)$. Besides this, we checked for VEGF levels $24 \mathrm{~h}$ after irradiation, the time point at which cell motility and cell proliferation was analyzed. The study by Kil in U-251 checked for VEGF levels $72 \mathrm{~h}$ after irradiation while the study by Hovinga et al. checked for VEGF 24, 48, and $72 \mathrm{~h}$ after irradiation with a minimum dose of 5 Gy. Nevertheless, it can be concluded, that in human GBM cell lines U-251 and U-373 VEGF and irradiation are able to speed up the cells, while axitinib has a strong decelerating effect. This is in line with in vivo data, in which high levels of VEGF are a negative factor for the prognosis (32). As the present data show that VEGF is a key player for migration, it is likely that forced invasion into the brain parenchyma is also driven by VEGF.

\section{VEGF Has an Autocrine Impact on Cell Proliferation}

We also examined the effects of VEGF and irradiation on cell proliferation, for which VEGF acts as a stimulator in endothelial cells and astrocytes $(7,27)$. Tumor cells in general show high levels of activation in the mitogen-related pathways, for example activation of the EGFR, which acts as a potent mitogen $(38,39)$. But in contrast to other cell types, we were not able to detect any significant effects of irradiation or added VEGF on cell proliferation in U-251 and U-373 cells. However, $24 \mathrm{~h}$ of treatment with axitinib reduced proliferation significantly in both cell lines. $\mathrm{Xu}$ et al. (43) demonstrated an increase in the proliferation of enriched GBM stem cells after stimulation with VEGF $(0.1 \mu \mathrm{g} / \mathrm{ml})$. Although this is an interesting result, an enriched GBM stem cell culture is not directly comparable with the situation in GBM patients (44-46). In addition, in vivo studies showed a reduction in blood vessel infiltration of the tumor in line with a reduction in tumor size by means of anti-angiogenic treatment $(47,48)$. In 2012, Lee et al. (49) demonstrated that the reduction of tumor size in glioma xenografts after antiangiogenic drugs is not only caused by a reduction of angiogenic proliferation, but also by the dependency of the tumor cells on autocrine and paracrine VEGF stimulation. This autocrine dependency was also proved by Mesti et al. in GBM cells (2014). Moreover, this study showed that the VEGF antibody bevacizumab is not able to reduce proliferation, whereas SU1498, a VEGF-R2 blocker, had a distinct anti-proliferative impact after $72 \mathrm{~h}$ of incubation, but no effect after $24 \mathrm{~h}$. It can be assumed that the lack of any stimulating VEGF effect on proliferation in our experiments is caused by a sufficient activation of VEGF signaling yet under control conditions. Additional proliferation experiments after 3 days of incubation in our lab yielded similar results than after $24 \mathrm{~h}$, with no significant differences to $24 \mathrm{~h}$ values.

Up to now, little data are available with respect to effects of axitinib on glioma cells in vitro (50-52). In our study the decrease in cell proliferation through axitinib treatment points out the important role of autocrine VEGF receptor stimulation in U-251 and U-373 cells. This decrease is allegeable by the fact that axitinib leads to cell cycle arrest, recently shown in U-251 cells (53).

\section{VEGF Receptor Signaling in GBM}

Vascular endothelial growth factor as a ligand for VEGF-R1 and VEGF-R2 activates several different pathways (Figures 4A,B). We demonstrated the expression of VEGF-R2 by immunohistochemistry and PCR in U-251 and U-373 cells. These data are in line with other studies that used different techniques such as Western blot, FACS and RT-PCR in different GBM cells $(26,30,31,54-57)$.

In glial cells, pathways which are activated by VEGF are less well understood, especially those that are linked to the actin network. Most VEGF dependent effects are mediated by VEGF-R2 (7). One very important aspect in the VEGF-R2 activation is the phosphorylation of tyrosine residue 1214. In endothelial cells, it was demonstrated that its phosphorylation, in combination 


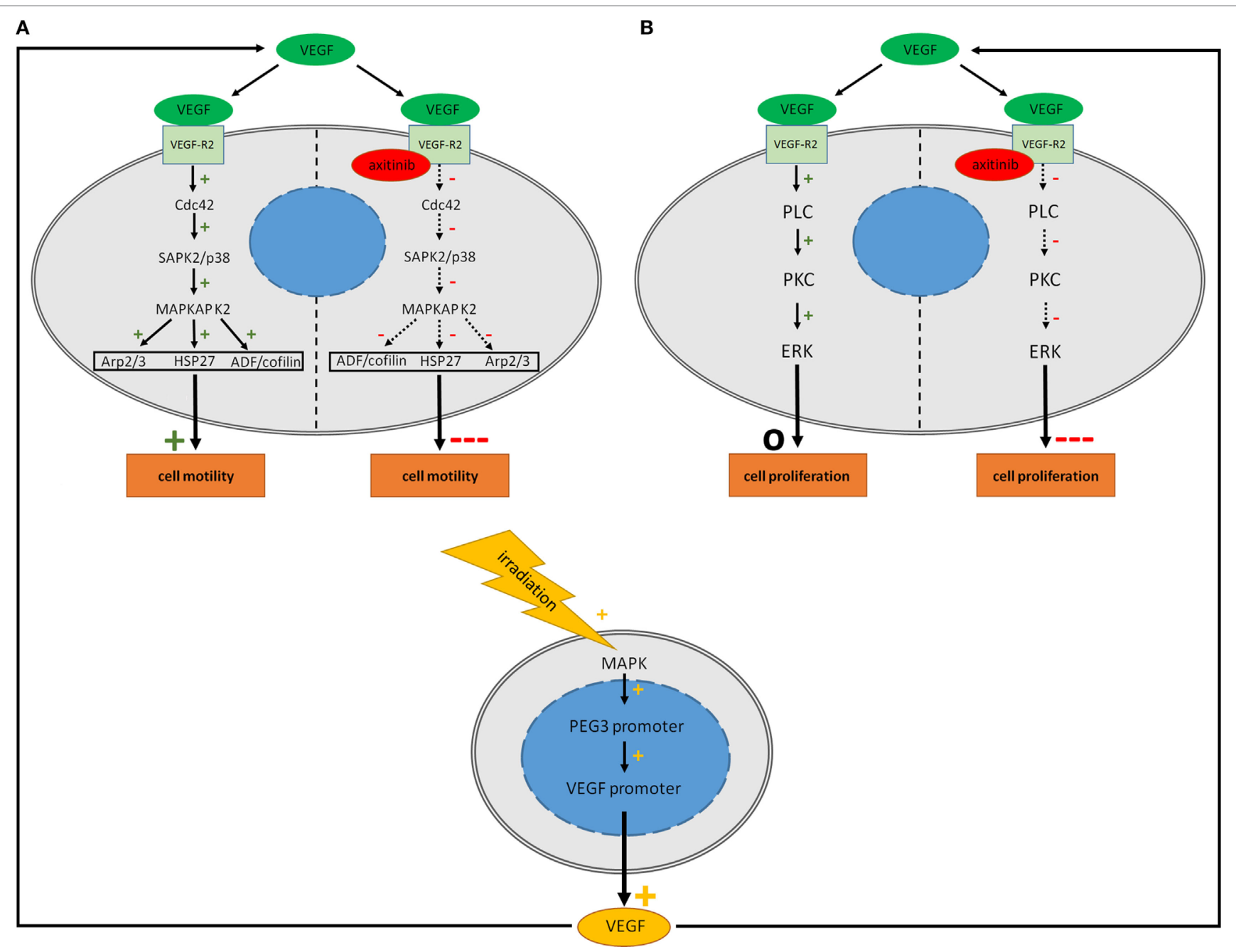

FIGURE 4 | Potential signaling in human glioblastoma cell lines after treatment with vascular endothelial growth factor (VEGF), irradiation and axitinib. VEGF activates multiple pathways including the Cdc42 and PLC pathways concerning cell migration and proliferation. It is supposed that stimulating effects of irradiation are mediated via enhanced synthesis of VEGF. Irradiation elevates VEGF biosynthesis of glioblastoma multiforme cells via MAPK activation. (A) Activation of the Cdc42 pathway by VEGF leads to an increased activation of Arp 2/3, HSP27, and ADF/cofilin resulting in an enhanced motility. Blockade of the VEGF-R2 by axitinib might decrease the activation of the Cdc42 pathway due to theoretical consideration resulting in a crucial decreased cell motility. (B) VEGF activates the PLC pathway which is involved in cell proliferation while axitinib might deactivate this pathway with impairment of cell proliferation. While motility is increased by VEGF, no positive effect on proliferation could be observed. This might be due to fully activated VEGF-pathways even under control conditions. Continuous arrows: evidence of the effect, dotted arrows: assumption of the effect.

with Cdc42 activation, leads to an activation of the SAPK2/p38 pathway, which stimulates MAPKAP K2 followed by phosphorylation of Hsp27 (Figure 4A). Furthermore, a stimulation of $\mathrm{ADF} /$ cofilin, Arp2/3, and WASP is involved in that pathway and acts as a re-organizer of the actin cytoskeleton with increased actin dynamics $(13,58,59)$. Besides this, the focal adhesion kinase (FAK) seems to be an important factor in cell migration and invasion, as VEGF-R2 activation results in a phosphorylation of FAK in endothelial cells (60) and in glioma (36). FAK is a protein tyrosine kinase which is expressed in most tissues, with particularly high levels in the brain $(61,62)$. Treatment with cerivastatin reversibly blocks FAK phosphorylation and could be a new strategy to inhibit cell invasion (63). Another pathway of motility that is closely related to FAK is the tyrosine kinase src, which is phosphorylated by stimulation through VEGF (64). These effects are mediated by VEGF-R1 and -R2, but preferentially by VEGF-R2 signaling $(36,65,66)$. In our study using PCR we showed semi-quantitatively that expression of VEGF-R1 (FLT1) is much lower than the expression of VEGF-R2 (KDR) which may explain that VEGF mediated effects in GBM are mainly based on VEGF-R2 signaling. Proliferation stimulating effects of VEGF-R2 are mediated by activation of phospholipase $\mathrm{C}$ following protein kinase $\mathrm{C}$ and extracellular signal regulated kinase (ERK) signaling (Figure 4B) $(67,68)$. All in all, these possible pathways might explain the role of VEGF signaling in cell motility and proliferation in GBM. 


\section{The Role of VEGF and Irradiation in GBM}

In conclusion, the effects of VEGF on GBM cells concerning motility are similar to the effects observed in astrocytes; however, in GBM cells the effects are slightly alleviated. One reason for this could be the high intrinsic VEGF production in GBM cells along with a relatively weak receptor expression level (31). We did not detect any stimulating effects of VEGF treatment on proliferation, which is not surprising, as there are other growth factors that might be over-stimulated in GBM. Even the concentration of endogenous VEGF under control conditions might be sufficient for a full activation of proliferation. However, in case that the VEGF receptor blocker axitinib passes through clinical trials, it could be a promising therapy for GBM patients, since two of the main characteristics of GBM could be disarmed; U-251 and U-373 lost their velocity, and proliferation could be reduced. Furthermore, irradiation mediated accelerating effects could be diminished. Therefore, a combination of axitinib and irradiation could be a potent strategy in the treatment of GBM.

\section{REFERENCES}

1. Adamson C, Kanu OO, Mehta AI, Di C, Lin N, Mattox AK, et al. Glioblastoma multiforme: a review of where we have been and where we are going. Expert Opin Investig Drugs (2009) 18(8):1061-83. doi:10.1517/13543780903052764

2. Stupp R, Mason WP, van den Bent MJ, Weller M, Fisher B, Taphoorn MJ, et al. Radiotherapy plus concomitant and adjuvant temozolomide for glioblastoma. N Engl J Med (2005) 352(10):987-96. doi:10.1056/NEJMoa043330

3. Giese A, Westphal M. Glioma invasion in the central nervous system. Neurosurgery (1996) 39(2):235-52. doi:10.1097/00006123-199608000-00001

4. Hottinger AF, Stupp R, Homicsko K. Standards of care and novel approaches in the management of glioblastoma multiforme. Chin JCancer (2014) 33(1):32-9. doi:10.5732/cjc.013.10207

5. Sanai N, Berger MS. Glioma extent of resection and its impact on patient outcome. Neurosurgery (2008) 62(4):753-64. doi:10.1227/01.neu. 0000318159.21731.cf

6. Laperriere N, Zuraw L, Cairncross G; Cancer Care Ontario Practice Guidelines Initiative Neuro-Oncology Disease Site Group. Radiotherapy for newly diagnosed malignant glioma in adults: a systematic review. Radiother Oncol (2002) 64(3):259-73. doi:10.1016/S0167-8140(02)00078-6

7. Ferrara N, Gerber HP, LeCouter J. The biology of VEGF and its receptors. Nat Med (2003) 9(6):669-76. doi:10.1038/nm0603-669

8. Senger DR, Galli SJ, Dvorak AM, Perruzzi CA, Harvey VS, Dvorak HF. Tumor cells secrete a vascular permeability factor that promotes accumulation of ascites fluid. Science (1983) 219(4587):983-5. doi:10.1126/science.6823562

9. Ferrara N, Davis-Smyth T. The biology of vascular endothelial growth factor. Endocr Rev (1997) 18(1):4-25. doi:10.1210/edrv.18.1.0287

10. Leung DW, Cachianes G, Kuang WJ, Goeddel DV, Ferrara N. Vascular endothelial growth factor is a secreted angiogenic mitogen. Science (1989) 246(4935):1306-9. doi:10.1126/science.2479986

11. Gerber HP, Dixit V, Ferrara N. Vascular endothelial growth factor induces expression of the antiapoptotic proteins Bcl-2 and A1 in vascular endothelial cells. J Biol Chem (1998) 273(21):13313-6. doi:10.1074/jbc.273.21.13313

12. Roberts DM, Kearney JB, Johnson JH, Rosenberg MP, Kumar R, Bautch VL. The vascular endothelial growth factor (VEGF) receptor Flt-1 (VEGFR-1) modulates Flk-1 (VEGFR-2) signaling during blood vessel formation. Am J Pathol (2004) 164(5):1531-5. doi:10.1016/S0002-9440(10)63711-X

13. Lamalice L, Houle F, Jourdan G, Huot J. Phosphorylation of tyrosine 1214 on VEGFR2 is required for VEGF-induced activation of Cdc42 upstream of SAPK2/p38. Oncogene (2004) 23(2):434-45. doi:10.1038/sj.onc.1207034

14. Barouk S, Hintz T, Li P, Duffy AM, MacLusky NJ, Scharfman HE. 17 $\beta$-estradiol increases astrocytic vascular endothelial growth factor (VEGF) in adult female rat hippocampus. Endocrinology (2011) 152(5):1745-51. doi:10.1210/ en.2010-1290

\section{ETHICS STATEMENT}

This article does not contain any studies with human participants or animals performed by any of the authors.

\section{AUTHOR CONTRIBUTIONS}

RK, VM, VT, HB, and CT conducted the study and analysis. RK, $\mathrm{HB}$, IA, and CT contributed to the concept and design of this study. The paper was written by all authors. All authors approved the final article.

\section{ACKNOWLEDGMENTS}

The authors would like to thank B. Priesch, S. Wenderdel, C. Grzelak, and A. Lodwig for their excellent technical assistance, as well as A. Lenz for her great secretarial work. The authors also thank D. Terheyden-Keighley for helpful critical discussions.

15. Liao D, Johnson RS. Hypoxia: a key regulator of angiogenesis in cancer Cancer Metastasis Rev (2007) 26(2):281-90. doi:10.1007/s10555-007-9066-y

16. Park JS, Qiao L, Su ZZ, Hinman D, Willoughby K, McKinstry R, et al. Ionizing radiation modulates vascular endothelial growth factor (VEGF) expression through multiplemitogen activated protein kinase dependent pathways. Oncogene (2001) 20(25):3266-80. doi:10.1038/sj.onc.1204931

17. Hendriksen EM, Span PN, Schuuring J, Peters JP, Sweep FC, van der Kogel AJ, et al. Angiogenesis, hypoxia and VEGF expression during tumor growth in a human xenograft tumor model. Microvasc Res (2009) 77(2):96-103. doi:10.1016/j.mvr.2008.11.002

18. Plate KH, Breier G, Weich HA, Risau W. Vascular endothelial growth factor is a potential tumor angiogenesis factor in human gliomas in vivo. Nature (1992) 359(6398):845-8. doi:10.1038/359845a0

19. Salmaggi A, Eoli M, Frigerio S, Silvani A, Gelati M, Corsini E, et al. Intracavitary VEGF, bFGF, IL-8, IL-12 levels in primary and recurrent malignant glioma. J Neurooncol (2003) 62(3):297-303. doi:10.1023/A:1023367223575

20. Hurwitz H, Fehrenbacher L, Novotny W, Cartwright T, Hainsworth J, Heim W, et al. Bevacizumab plus irinotecan, fluorouracil, and leucovorin for metastatic colorectal cancer. N Engl J Med (2004) 350(23):2335-42. doi:10.1056/NEJMoa032691

21. Presta LG, Chen H, O'Connor SJ, Chisholm V, Meng YG, Krummen L, et al. Humanization of an anti-vascular endothelial growth factor monoclonal antibody for the therapy of solid tumors and other disorders. Cancer Res (1997) 57(20):4593-9.

22. Chinot OL, Wick W, Mason W, Henriksson R, Saran F, Nishikawa R, et al. Bevacizumab plus radiotherapy-temozolomide for newly diagnosed glioblastoma. N Engl J Med (2014) 370(8):709-22. doi:10.1056/NEJMoa1308345

23. Rahmathulla G, Hovey EJ, Hashemi-Sadraei N, Ahluwalia MS. Bevacizumab in high-grade gliomas: a review of its uses, toxicity assessment, and future treatment challenges. Onco Targets Ther (2013) 6:371-89. doi:10.2147/OTT. S38628

24. Hutson TE, Lesovoy V, Al-Shukri S, Stus VP, Lipatov ON, Bair AH, et al. Axitinib versus sorafenib as first-line therapy in patients with metastatic renalcell carcinoma: a randomised open-label phase 3 trial. Lancet Oncol (2013) 14(13):1287-94. doi:10.1016/S1470-2045(13)70465-0

25. Kelly RJ, Rixe O. Axitinib - a selective inhibitor of the vascular endothelial growth factor (VEGF) receptor. Target Oncol (2009) 4(4):297-305. doi:10.1007/s11523-009-0126-9

26. Lee J, Lee J, Yu H, Choi K, Choi C. Differential dependency of human cancer cells on vascular endothelial growth factor-mediated autocrine growth and survival. Cancer Lett (2011) 309(2):145-50. doi:10.1016/j.canlet.2011.05.026

27. Wuestefeld R, Chen J, Meller K, Brand-Saberi B, Theiss C. Impact of vegf on astrocytes: analysis of gap junctional intercellular communication, proliferation, and motility. Glia (2012) 60(6):936-47. doi:10.1002/glia.22325 
28. Zygalaki E, Tsaroucha EG, Kaklamanis L, Lianidou ES. Quantitative real-time reverse transcription PCR study of the expression of vascular endothelial growth factor (VEGF) splice variants and VEGF receptors (VEGFR-1 and VEGFR-2) in non small cell lung cancer. Clin Chem (2007) 53(8):1433-9. doi:10.1373/clinchem.2007.086819

29. Bühler H, Strohm GL, Nguemgo-Kouam P, Lamm H, Fakhrian K, Adamietz IA. The therapeutic effect of photon irradiation on viable glioblastoma cells is reinforced by hyperbaric oxygen. Anticancer Res (2015) 35:1977-83.

30. Knizetova P, Ehrmann J, Hlobilkova A, Vancova I, Kalita O, Kolar Z, et al. Autocrine regulation of glioblastoma cell cycle progression, viability and radioresistance through the VEGF-VEGFR2 (KDR) interplay. Cell Cycle (2008) 7(16):2553-61. doi:10.4161/cc.7.16.6442

31. Mentlein R, Forstreuter F, Mehdorn HM, Held-Feindt J. Functional significance of vascular endothelial growth factor receptor expression on human glioma cells. J Neurooncol (2004) 67(1-2):9-18. doi:10.1023/B:NEON.0000021737.89357.cc

32. Oehring RD, Miletic M, Valter MM, Pietsch T, Neumann J, Fimmers R, et al. Vascular endothelial growth factor (VEGF) in astrocytic gliomas - a prognostic factor? J Neurooncol (1999) 45(2):117-25. doi:10.1023/A:1006333005563

33. Geng L, Donnelly E, McMahon G, Lin PC, Sierra-Rivera E, Oshinka H, et al. Inhibition of vascular endothelial growth factor receptor signaling leads to reversal of tumor resistance to radiotherapy. Cancer Res (2001) 61(6):2413-9.

34. Gupta VK, Jaskowiak NT, Beckett MA, Mauceri HJ, Grunstein J, Johnson RS, et al. Vascular endothelial growth factor enhances endothelial cell survival and tumor radioresistance. Cancer J (2002) 8(1):47-54. doi:10.1097/ 00130404-200201000-00009

35. Gorski DH, Beckett MA, Jaskowiak NT, Calvin DP, Mauceri HJ, Salloum RM, et al. Blockage of the vascular endothelial growth factor stress response increases the antitumor effects of ionizing radiation. Cancer Res (1999) 59(14):3374-8.

36. Kil WJ, Tofilon PJ, Camphausen K. Post-radiation increase in VEGF enhances glioma cell motility in vitro. Radiat Oncol (2012) 7:25. doi:10.1186/1748-717X-7-25

37. Porkholm M, Valanne L, Lönnqvist T, Holm S, Lannering B, Riikonen P, et al. Radiation therapy and concurrent topotecan followed by maintenance triple anti-angiogenic therapy with thalidomide, etoposide, and celecoxib for pediatric diffuse intrinsic pontine glioma. Pediatr Blood Cancer (2014) 61(9):1603-9. doi:10.1002/pbc.25045

38. Liu M, Yang Y, Wang C, Sun L, Mei C, Yao W, et al. The effect of epidermal growth factor receptor variant III on glioma cell migration by stimulating ERK phosphorylation through the focal adhesion kinase signaling pathway. Arch Biochem Biophys (2010) 502(2):89-95. doi:10.1016/j.abb.2010.07.014

39. Sieg DJ, Hauck CR, Ilic D, Klingbeil CK, Schaefer E, Damsky CH, et al. FAK integrates growth-factor and integrin signals to promote cell migration. Nat Cell Biol (2000) 2(5):249-56. doi:10.1038/35010517

40. Ghosh S, Kumar A, Tripathi RP, Chandna S. Connexin-43 regulates p38-mediated cell migration and invasion induced selectively in tumour cells by low doses of $\gamma$-radiation in an ERK-1/2-independent manner. Carcinogenesis (2014) 35(2):383-95. doi:10.1093/carcin/bgt303

41. Hovinga KE, Stalpers LJ, van Bree C, Donker M, Verhoeff JJ, Rodermond HM, et al. Radiation-enhanced vascular endothelial growth factor (VEGF) secretion in glioblastoma multiforme cell lines - a clue to radioresistance? J Neurooncol (2005) 74(2):99-103. doi:10.1007/s11060-004-4204-7

42. Nachbichler SB, Schupp G, Ballhausen H, Niyazi M, Belka C. Temozolomide during radiotherapy of glioblastoma multiforme: daily administration improves survival. Strahlenther Onkol (2017). doi:10.1007/s00066-017-1110-4

43. Xu C, Wu X, Zhu J. VEGF promotes proliferation of human glioblastoma multiforme stem-like cells through VEGF receptor 2. ScientificWorldJournal (2013) 2013:417413. doi:10.1155/2013/417413

44. Cho DY, Lin SZ, Yang WK, Hsu DM, Lin HL, Lee HC, et al. The role of cancer stem cells (CD133(+)) in malignant gliomas. Cell Transplant (2011) 20(1):121-5. doi:10.3727/096368910X532774

45. Oka N, Soeda A, Noda S, Iwama T. Brain tumor stem cells from an adenoidglioblastoma multiforme. Neurol Med Chir (Tokyo) (2009) 49(4):146-50; discussion 150-1. doi:10.2176/nmc.49.146

46. Singh SK, Hawkins C, Clarke ID, Squire JA, Bayani J, Hide T, et al. Identification of human brain tumour initiating cells. Nature (2004) 432(7015):396-401. doi: $10.1038 /$ nature 03128
47. Hanyu A, Kojima K, Hatake K, Nomura K, Murayama H, Ishikawa Y, et al. Functional in vivo optical imaging of tumor angiogenesis, growth, and metastasis prevented by administration of anti-human VEGF antibody in xenograft model of human fibrosarcoma HT1080 cells. Cancer Sci (2009) 100(11):2085-92. doi:10.1111/j.1349-7006.2009.01305.x

48. Keunen O, Johansson M, Oudin A, Sanzey M, Rahim SA, Fack F, et al. AntiVEGF treatment reduces blood supply and increases tumor cell invasion in glioblastoma. Proc Natl Acad Sci U S A (2011) 108(9):3749-54. doi:10.1073/ pnas. 1014480108

49. Lee J, Ku T, Yu H, Chong K, Ryu SW, Choi K, et al. Blockade of VEGF-A suppresses tumor growth via inhibition of autocrine signaling through FAK and AKT. Cancer Lett (2012) 318(2):221-5. doi:10.1016/j.canlet.2011. 12.014

50. Doloff JC, Waxman DJ. VEGF receptor inhibitors block the ability ofmetronomically dosed cyclophosphamide to activate innate immunity-induced tumor regression. Cancer Res (2012) 72(5):1103-15. doi:10.1158/0008-5472. CAN-11-3380

51. Lu L, Saha D, Martuza RL, Rabkin SD, Wakimoto H. Single agent efficacy of the VEGFR kinase inhibitor axitinib in preclinical models of glioblastoma. J Neurooncol (2015) 121(1):91-100. doi:10.1007/s11060-014-1612-1

52. Ma J, Chen CS, Blute T, Waxman DJ. Antiangiogenesis enhances intratumoral drug retention. Cancer Res (2011) 71(7):2675-85. doi:10.1158/0008-5472. CAN-10-3242

53. Morelli MB, Amantini C, Nabissi M, Cardinali C, Santoni M, Bernardini G, et al. Axitinib induces senescence-associated cell death and necrosis in glioma cell lines: the proteasome inhibitor, bortezomib, potentiates axitinib-induced cytotoxicity in a p21(Waf/Cip1) dependent manner. Oncotarget (2017) 8(2):3380-95. doi:10.18632/oncotarget.13769

54. Francescone R, Scully S, Bentley B, Yan W, Taylor SL, Oh D, et al. Glioblastomaderived tumor cells induce vasculogenic mimicry through Flk-1 protein activation. J Biol Chem (2012) 287(29):24821-31. doi:10.1074/jbc.M111. 334540

55. Lucio-Eterovic AK, Piao Y, de Groot JF. Mediators of glioblastoma resistance and invasion during antivascular endothelial growth factor therapy. Clin Cancer Res (2009) 15(14):4589-99. doi:10.1158/1078-0432.CCR-09-0575

56. Mesti T, Savarin P, Triba MN, Le Moyec L, Ocvirk J, Banissi C, et al. Metabolic impact of anti-angiogenic agents on U87 glioma cells. PLoS One (2014) 9(6):e99198. doi:10.1371/journal.pone.0099198

57. Yao X, Ping Y, Liu Y, Chen K, Yoshimura T, Liu M, et al. Vascular endothelial growth factor receptor 2 (VEGFR-2) plays a key role in vasculogenic mimicry formation, neovascularization and tumor initiation by Glioma stem-like cells. PLoS One (2013) 8(3):e57188. doi:10.1371/journal.pone.0057188

58. Rousseau S, Houle F, Landry J, Huot J. p38 MAP kinase activation by vascular endothelial growth factor mediates actin reorganization and cell migration in human endothelial cells. Oncogene (1997) 15(18):2169-77. doi:10.1038/ sj.onc. 1201380

59. Rousseau S, Houle F, Kotanides H, Witte L, Waltenberger J, Landry J, et al. Vascular endothelial growth factor (VEGF)-driven actin-based motility is mediated by VEGFR2 and requires concerted activation of stress-activated protein kinase 2 (SAPK2/p38) and geldanamycin-sensitive phosphorylation of focal adhesion kinase. J Biol Chem (2000) 275(14):10661-72. doi:10.1074/ jbc.275.14.10661

60. Abedi H, Zachary I. Vascular endothelial growth factor stimulates tyrosine phosphorylation and recruitment to new focal adhesions of focal adhesion kinase and paxillin in endothelial cells. J Biol Chem (1997) 272(24):15442-51. doi:10.1074/jbc.272.24.15442

61. André E, Becker-André M. Expression of an N-terminally truncated form of human focal adhesion kinase in brain. Biochem Biophys Res Commun (1993) 190(1):140-7. doi:10.1006/bbrc.1993.1022

62. Grant SG, Karl KA, Kiebler MA, Kandel ER. Focal adhesion kinase in the brain: novel subcellular localization and specific regulation by Fyn tyrosine kinase in mutant mice. Genes Dev (1995) 9(15):1909-21. doi:10.1101/gad.9.15.1909

63. Obara S, Nakata M, Takeshima H, Kuratsu J, Maruyama I, Kitajima I. Inhibition of migration of human glioblastoma cells by cerivastatin in association with focal adhesion kinase (FAK). Cancer Lett (2002) 185(2):153-61. doi:10.1016/ S0304-3835(02)00278-1

64. Calalb MB, Polte TR, Hanks SK. Tyrosine phosphorylation of focal adhesion kinase at sites in the catalytic domain regulates kinase activity: a role for Src family kinases. Mol Cell Biol (1995) 15(2):954-63. doi:10.1128/MCB.15.2.954 
65. Chou MT, Wang J, Fujita DJ. Src kinase becomes preferentially associated with the VEGFR, KDR/Flk-1, following VEGF stimulation of vascular endothelial cells. BMC Biochem (2002) 3:32. doi:10.1186/1471-20913-32

66. Munshi N, Groopman JE, Gill PS, Ganju RK. c-Src mediates mitogenic signals and associates with cytoskeletal proteins upon vascular endothelial growth factor stimulation in Kaposi's sarcoma cells. J Immunol (2000) 164(3):1169-74. doi:10.4049/jimmunol.164.3.1169

67. Matsumoto T, Mugishima H. Signal transduction via vascular endothelial growth factor (VEGF) receptors and their roles in atherogenesis. J Atheroscler Thromb (2006) 13(3):130-5. doi:10.5551/jat.13.130

68. Takahashi T, Yamaguchi S, Chida K, Shibuya M. A single autophosphorylation site on KDR/Flk-1 is essential for VEGF-A-dependent activation of
PLC-gamma and DNA synthesis in vascular endothelial cells. EMBO J (2001) 20(11):2768-78. doi:10.1093/emboj/20.11.2768

Conflict of Interest Statement: All the authors declare that research has been conducted without any commercial or financial relationships which could be construed as a potential conflict of interest.

Copyright (c) 2017 Krcek, Matschke, Theis, Adamietz, Bühler and Theiss. This is an open-access article distributed under the terms of the Creative Commons Attribution License (CC BY). The use, distribution or reproduction in other forums is permitted, provided the original author(s) or licensor are credited and that the original publication in this journal is cited, in accordance with accepted academic practice. No use, distribution or reproduction is permitted which does not comply with these terms. 